Curr Opin Crit Care. 2015 February ; 21(1): 82-90. doi:10.1097/MCC.0000000000000174.

\title{
Prevention of ARDS
}

\author{
Emir Festic ${ }^{1}$, Daryl J. Kor ${ }^{2}$, and Ognjen Gajic ${ }^{3}$ \\ ${ }^{1}$ Pulmonary and Critical Care Medicine, Mayo Clinic, Jacksonville, Florida \\ ${ }^{2}$ Anestesiology and Critical Care Medicine, Mayo Clinic, Rochester, Minnesota \\ ${ }^{3}$ Pulmonary and Critical Care Medicine, Mayo Clinic, Rochester, Minnesota
}

\begin{abstract}
Purpose of review-The paucity of effective therapeutic interventions in patients with the acute respiratory distress syndrome (ARDS) combined with overwhelming evidence on the importance of timely implementation of effective therapies to the critically ill patients have resulted in a recent shift in ARDS research. Increasingly, efforts are being directed towards early identification of patients at risk with a goal of prevention and early treatment, prior to development of the fully established syndrome. The focus of this review is on the prevention of ARDS in patients without this condition at the time of their healthcare encounter.
\end{abstract}

Recent findings-The primary thematic categories presented in this review article include: Early identification of patients at risk of developing ARDS, optimization of care delivery and its impact on the incidence of ARDS, pharmacological prevention of ARDS, prevention of postoperative ARDS, and challenges and opportunities with ARDS prevention studies.

Summary-Recent improvements in clinical care delivery have been associated with a decrease in the incidence of hospital acquired ARDS. Despite the initial challenges, research in ARDS prevention has become increasingly feasible with several randomized controlled trials on ARDS prevention completed or on the way.

\section{Keywords}

ARDS; prevention; quality improvement

\section{Introduction}

Almost 40 years after the initial description of acute respiratory distress syndrome (ARDS)

(1) only a few interventions demonstrated the outcome benefit in this devastating complication of critical illness or injury. The current therapy is largely supportive, including lung-protective mechanical ventilation(2-4) and restrictive fluid and blood products administration.(5) However, these "supportive" therapies do not reverse the pathophysiological processes underlying ARDS; rather they limit further iatrogenic injury to

Corresponding author: Emir Festic, MD, 4500 San Pablo Rd, Jacksonville, FL 32224, 904-956-3331, Festic.Emir@mayo.edu. Conflicts of interest: Dr. Festic has no conflicts of interest relevant to this publication. Dr. Kor receives royalties from Up-to-Date for authoring a chapter on the topic of Transfusion-Related Acute Lung Injury. Mayo Clinic and Dr. Ognjen Gajic hold the patent application on critical care related software applications licensed to Ambient Clinical Analytics Inc. 
lungs in patients with prevalent ARDS. Therefore, current supportive therapies for ARDS are perhaps better regarded as prevention of further complications or worsening of the underlying disease (tertiary prevention) rather than effective therapies for inflammatory lung edema.

The relative lack of effective therapeutic interventions in ARDS combined with overwhelming evidence on the importance of timely implementation of effective therapies in the setting of critical illness has resulted in a recent shift in ARDS research. More specifically, research efforts are increasingly being directed towards the early identification of patients at risk with a goal of prevention before ARDS is fully established. In 2010, an NHBLI workshop on future clinical research in acute lung injury (ALI) recommended development of strategies to perform ALI prevention trials.(6) In 2013, the Acute Respiratory Distress Syndrome (ARDS) Network was retired and replaced with the Clinical Trials Network for the Prevention and Early Treatment of Acute Lung Injury (http:// grants.nih.gov/grants/guide/rfa-files/RFA-HL-14-014.html, accessed on August 21, 2014). This paradigm shift in ARDS research emphasizes the increasingly recognized importance of ARDS prevention. The focus of this review is prevention of ARDS in patients without lung injury at the time of the healthcare encounter.

\section{Early identification of patients at risk of developing ARDS}

In order to study plausible interventions and treatments for the prevention of ARDS, a key barrier is its relatively low $(\sim 1 \%)$ prevalence among hospitalized patients.(7) A recent multicenter observational cohort study of 5,584 patients from 22 hospitals, identified key predisposing conditions and risk modifiers for ARDS and refined and validated a prediction model to identify patients at high risk for ARDS at the time of hospital admission.(8) Based on routinely available clinical data, a novel Lung Injury Prediction Score (LIPS) at a cutoff of $\geq 4$ demonstrated a positive predictive value for ARDS of $18 \%$ with a negative predictive value of $97 \%$ (Figure 1). While the suboptimal predictive accuracy does not support its use in everyday clinical practice, LIPS has enabled enrollment in novel clinical trials of ARDS prevention (actively recruiting LIPS-A, NCT01504867 and LIPS-B, NCT01783821). Using similar methodologies, two surgical lung injury prediction models (SLIP and SLIP-2) have also been developed for the identification of patients at high risk of postoperative lung injury. $(9,10)$

Notably, there have been other recent attempts to predict early ARDS. Levitt and al. derived an Early Acute Lung Injury Score, dependent on the oxygen requirement, respiratory rate and presence of immunosuppression in patients with bilateral infiltrates on chest imaging. (11) The score performed similarly to the LIPS, was not limited to the first 6 hours of hospitalization and is relatively simple to calculate. In a secondary analysis of the LIPS cohort, we have shown that the ratio of oxygen saturation by pulse oximetry to the fraction of inspired oxygen $(\mathrm{SpO} 2 / \mathrm{FiO} 2)$ is an independent predictor of early ARDS development, even after adjustment for age, comorbidities, the APACHE 2 score and all other LIPS variables.(12) The main limitation to the clinical use of $\mathrm{SpO} / \mathrm{FiO} 2$ in prediction of ARDS is the lack of standardized measurement of $\mathrm{FiO} 2$ in spontaneously breathing patients. 
Nevertheless, the broad availability and the simplicity of $\mathrm{SpO} 2 / \mathrm{FiO} 2$ calculations are obvious advantages.

\section{Improvements in clinical care delivery and the impact on ARDS development}

Importantly, ARDS is rarely present at the time of the initial healthcare encounter. Rather, it typically develops during the hospital course, usually between days 2 and 5 in patients with predisposing conditions or risk factors.(8) Therefore, ARDS may be thought of as an iatrogenic complication with the potential for avoidance with optimal care delivery. Hospitalized patients are frequently exposed to various potentially harmful factors that may modify the inherent risk of ARDS development. This concept is often referred to as the multi-hit theory of ARDS pathogenesis. The number of such "hits" or harmful in-hospital exposures is directly proportional to the likelihood of ARDS development.(13) If one accepts these plausible concepts, two essential conclusions arise: 1) there is a window of opportunity for ARDS prevention that begins at the time of the initial healthcare encounter; and 2) by limiting high-risk exposures, ARDS may be preventable.

\section{Olmsted county data experience}

A retrospective, population-based study of Olmsted County residents reported a decrease in the incidence of hospital-acquired ARDS by more than half during the 8-year evaluation interval. Although causal relationships could not be determined, multiple changes in critical care structure and care delivery were implemented concurrent with the falling rate of ARDS. (14) Notably, the decrease in ARDS incidence was observed despite a stable incidence of community-acquired ARDS, an increase in the population's severity of illness and comorbid burden, and a higher prevalence of predisposing conditions for ARDS over the same 8-year period. The ARDS case-fatality rate over this same interval did not change, highlighting a potentially more meaningful opportunity for ARDS prevention when compared to the treatment of established ARDS. Several of the factors associated with ARDS development in this study, have been confirmed in other pertinent publications.(15-17) In a single-center study of ventilated patients without ARDS at the onset of mechanical ventilation, we have shown the importance of high tidal volume ventilation(15), which has been confirmed in a recent meta-analysis.(18) The importance of restrictive transfusion, use of male-donor predominant plasma transfusion(16) as well as timely treatment of sepsis,(17) have all been subsequently confirmed.

\section{Other factors that can serve as potential prevention targets}

The role of atelectasis and recumbency in ARDS pathogenesis, particularly in obese patients, has recently been highlighted.(19) This intriguing perspective focuses on the adverse effects of body position, spontaneous and mechanical hyperventilation on surfactant, surface tension and development of atelectasis (Figure 2). Therefore, the modification of current care relative to patient positioning and sedation may impact surfactant dysfunction and resulting atelectasis, ultimately mitigating risk for ARDS. 
Gastric to pulmonary aspiration was identified as a principal cause of hospital-acquired ARDS back in 1980s.(20) In the LIPS cohort, aspiration represented one of the most common major risk-factors for ARDS.(21) Additional potentially modifiable risk factors include the use of strict lung-protective ventilation at the outset (NCT02070666), neuromuscular blockade,(3) limitation of oxygen support with lower oxygen saturation targets,(22) targeted fluid resuscitation and restrictive transfusion of blood products,(23) avoidance of hyperventilation in spontaneously breathing patients and striving for early extubation and early mobilization,(19) among others. All of these interventions have the potential to limit unnecessary and potentially harmful "hits" that may eventually result in fully established ARDS.

\section{Checklist for Lung Injury Prevention}

To be truly effective in mitigating the occurrence of ARDS, the simple identification of potentially modifiable factors is not sufficient. It is important to ensure that best evidence is not only disseminated, but implemented in a timely manner and continually assessed for their use and impact.(24-26). To this extent, LIPS investigators have formulated and implemented the Checklist for Lung Injury Prevention (CLIP),(27) which contains the key elements for standardizing the care of patients at risk enrolled in clinical trials of ARDS (Figure 3).

\section{Pharmacological prevention}

In addition to the improvements in clinical care delivery, we must continue efforts to identify effective new therapies that target the pathophysiological pathways underlying ARDS. Figure 4 provides a list of emerging pharmacological interventions for ARDS prevention.(28)

\section{Inhaled medications}

The notion of delivering medications with preventative potential directly to the lungs, thereby avoiding systemic side effects, is very attractive. Perkins et al. recently investigated inhaled salmeterol for ARDS prevention.(29) Over a 3-year period, they recruited 362 patients undergoing esophagectomy in 12 centers in the United Kingdom. Though the incidence of ARDS did not differ between salmeterol and placebo groups, postoperative adverse events (primarily pneumonia) were less frequent in the former. Additionally, in a translational substudy of 53 patients, salmeterol reduced several biomarkers of alveolar inflammation and epithelial injury.

The ongoing Lung Injury Prevention Study with Budesonide and Beta agonist formoterol (LIPS-B) is the first phase 2 clinical trial to study inhaled corticosteroids in combination with a long-acting beta agonist for prevention of ARDS (NCT01783821). In addition to direct anti-inflammatory properties, $(30,31)$ these drugs may act synergistically to improve peripheral delivery of the drugs.(32) In LIPS-B trial, the patients at risk for ARDS, as judged by a high LIPS score ( $\geq 4$ ) are recruited less than 12 hours from their presentation to the hospital, and receive inhaled medications or identically appearing placebo twice daily for up to 10 doses. The primary aim of the study is to inform whether the treatment with inhaled 
budesonide and formoterol can alleviate pulmonary dysfunction in patients at risk for ARDS.

In a small clinical trial enrolling 50 patients requiring mechanical ventilation for longer than 48 hours, inhaled heparin was associated with fewer days of mechanical ventilation when compared to placebo.(33) Experimental and observational clinical data suggested that inhaled anticoagulants might be associated with improved survival in patients with smoke inhalation-induced lung injury.(34) Several animal studies have demonstrated potential of nebulized hypertonic saline to ameliorate inflammatory and oxidative stress pathways of lung injury $(35,36)$ and the phase I/II clinical trial is on the way.

\section{Systemic medications}

Dysregulated inflammation, coagulation and oxidative stress play central roles in ARDS pathophysiology (37) and future mechanistic ARDS prevention trials are likely to target these pathways. In addition, platelet activation has been increasingly linked to both ARDS development and resolution. $(38,39)$ Both animal data and observational studies suggest aspirin can modulate these platelet-mediated processes and prevent or attenuate lung injury. (40-43) Given its wide availability, good safety profile, potential to decrease both inflammation and vascular permeability, and potential impact on immune function, aspirin is a prime candidate for prevention of ARDS by systemic delivery. The ongoing NIHsponsored multicenter randomized placebo-controlled, LIPS-A trial (NCT01504867), will address whether the daily administration of aspirin up to 7 days can prevent or attenuate ARDS in patients at risk.(27)

Other systemic medications have shown to be effective in ameliorating lung injury and are being currently investigated. A selective inhibitor of p38 alpha mitogen-activated protein kinase plays a major role in the regulation of the inflammatory cytokines. It is currently being investigated in a multicenter clinical trial accruing patients at risk for ARDS due to trauma (NCT00996840). Efficacy in ARDS prevention of bevacizumab, a recombinant humanized monoclonal antibody that inhibits vascular endothelial growth factor $\mathrm{A}$, has also been studied in an ongoing clinical trial (NCT01314066).

\section{Prevention of postoperative ARDS: experimental clinical laboratory for prevention studies}

ARDS is a common and frequently lethal cause of postoperative respiratory failure, accounting for approximately $35 \%$ of cases.(44) The overall incidence of postoperative ARDS is estimated at approximately $3 \%,(44)$ but rates vary greatly for different surgical procedures. $(8,9)$ Specifically, complex cardiac, thoracic and aortic vascular surgeries have been consistently associated with the highest-rates of postoperative ARDS. Likewise, emergency surgery also appears to portend increased risk for this life-threatening postoperative respiratory complication. $(10,45)$ Notably, postoperative ARDS has been associated with up to $45 \%$ mortality.(44)

As in the non-surgical setting, a key barrier to preventing postoperative ARDS has been our inability to identify those at greatest risk. In an effort to address this limitation, recent 
investigations have reported prediction models that can be used to identify a more targeted study population with greater risk for developing postoperative ARDS. $(9,46)$ More recently, a prediction model has been developed for more heterogeneous surgical populations including those undergoing both elective and emergency surgery as well as those with concomitant major risk factors for ARDS.(10)

The perioperative environment provides a unique opportunity to better understand ARDS mechanisms. Specifically, the above-mentioned ARDS prediction models can be used to facilitate the identification of patients at particular risk for postoperative ARDS prior to their surgical procedure. In doing so, patients may be enrolled before the major risks for ARDS have been experienced. As a result, ARDS pathogenesis can be studied from a relatively healthy (preoperative) state to the full ARDS phenotype, in contrast to patients who are admitted through the emergency department.

\section{Challenges and opportunities of ARDS prevention studies}

The design and conduct of ARDS prevention trials pose numerous challenges. Patients need to be identified, consented and enrolled very early in their hospital course. For example, the inhaled medications in LIPS-B trial are to be delivered not later than 4 hours after the randomization, regardless of the time of the day (or night). The time-sensitive nature of these interventional trials raise challenges that require innovative patient enrollment strategies (e.g. novel informatics approaches to patient identification(47)), different approaches to informed consent (surrogate, phone, deferred or community consent) as well as multispecialty collaboration (emergency medicine physicians, hospitalists, intensivists, anesthesiologists, surgeons, pharmacists, respiratory therapists, etc).

In addition to the challenges of early identification and enrollment, there are other barriers that must be addressed as well. While the development of ARDS is a logical primary outcome, the relatively low positive predictive value of the prediction scores poses limitations. Specifically, only a small proportion of patients at risk will progress to fully established ARDS, which increases the sample size requirement, duration and associated cost of the clinical trials. Therefore, the use of alternative, surrogate outcomes may be considered. Particularly attractive seems to be derangement in oxygenation, given its increasingly recognized importance in likelihood for the development as well as prognosis of ARDS. $(11,12,48)$ Alternatively, an extravascular lung water measurement could potentially be a useful surrogate outcome. $(49,50)$ However, an intervention that positively affects surrogate outcome might not necessarily improve but rather could pose harmful effect on patient-important outcomes.(2)

\section{Conclusion}

The importance of ARDS prevention has been increasingly recognized by the scientific community. Identifying patients at risk for ARDS early in their healthcare encounter and improvements in care delivery for those deemed to be at risk of this life-threatening syndrome have been associated with reduced incidence of ARDS among hospitalized 
patients. Moreover, systematic testing and implementation of pharmacological prevention strategies has a potential to further decrease the burden of ARDS.

\section{Acknowledgments}

Funding: NIH 5KL2 TR000136, TR00135-09J ${ }^{1}$, NIH U01 HL108712-01, DHHS 1C1CMS 330964² ${ }^{2}$ NIH K23 HL112855- $02^{3}$

Dr. Festic: NIH 5KL2 TR000136, TR00135-09J

Dr. Gajic: NIH U01 HL108712-01, DHHS 1C1CMS 330964

Dr. Kor: NIH K23 HL112855-02

\section{References}

1. Ashbaugh DG, Bigelow DB, Petty TL, Levine BE. Acute respiratory distress in adults. Lancet. 1967; 2(7511):319-23. [PubMed: 4143721]

2. Ventilation with lower tidal volumes as compared with traditional tidal volumes for acute lung injury and the acute respiratory distress syndrome. The Acute Respiratory Distress Syndrome Network. N Engl J Med. 2000; 342(18):1301-8. [PubMed: 10793162]

3. Papazian L, Forel JM, Gacouin A, Penot-Ragon C, Perrin G, Loundou A, et al. Neuromuscular blockers in early acute respiratory distress syndrome. N Engl J Med. 2010; 363(12):1107-16. [PubMed: 20843245]

4. Guerin C, Reignier J, Richard JC, Beuret P, Gacouin A, Boulain T, et al. Prone positioning in severe acute respiratory distress syndrome. N Engl J Med. 2013 Jun 6; 368(23):2159-68. [PubMed: 23688302]

5. Wiedemann HP, Wheeler AP, Bernard GR, Thompson BT, et al. National Heart L, Blood Institute Acute Respiratory Distress Syndrome Clinical Trials N. Comparison of two fluid-management strategies in acute lung injury. N Engl J Med. 2006; 354(24):2564-75. [PubMed: 16714767]

6. Spragg RG, Bernard GR, Checkley W, Curtis JR, Gajic O, Guyatt G, et al. Beyond mortality: future clinical research in acute lung injury. Am J Respir Crit Care Med. 2010; 181(10):1121-7. [PubMed: 20224063]

7. Rubenfeld GD, Herridge MS. Epidemiology and outcomes of acute lung injury. Chest. 2007; 131(2):554-62. [PubMed: 17296661]

8. Gajic O, Dabbagh O, Park PK, Adesanya A, Chang SY, Hou P, et al. Early identification of patients at risk of acute lung injury: evaluation of lung injury prediction score in a multicenter cohort study. Am J Respir Crit Care Med. 2011; 183(4):462-70. [PubMed: 20802164]

9. Kor DJ, Warner DO, Alsara A, Fernandez-Perez ER, Malinchoc M, Kashyap R, et al. Derivation and diagnostic accuracy of the surgical lung injury prediction model. Anesthesiology. 2011; 115(1): 117-28. [PubMed: 21694510]

10*. Kor DJ, Lingineni RK, Gajic O, Park PK, Blum JM, Hou PC, et al. Predicting risk of postoperative lung injury in high-risk surgical patients: a multicenter cohort study. Anesthesiology. 2014; 120(5):1168-81. In this secondary analysis of a multicenter, prospective cohort investigation evaluating high-risk patients undergoing surgery, preoperative ARDS risk factors and risk modifiers were used to derive refined risk-prediction model, designated SLIP-2. Nine independent predictors of ARDS were identified. The SLIP-2 outperformed original SLIP with an area under the receiver operating characteristic curve of $0.84 ; 0.81-0.88$. Once validated in an independent sample, this tool may help identify surgical patients at high risk for ARDS. [PubMed: 24755786]

11*. Levitt JE, Calfee CS, Goldstein BA, Vojnik R, Matthay MA. Early acute lung injury: criteria for identifying lung injury prior to the need for positive pressure ventilation*. Crit Care Med. 2013; 41(8):1929-37. In this single center prospective observational cohort study, a novel early acute lung injury (EALI) prediction score was developed. EALI greater than or equal to 2 identified patients who progressed to ARDS within median of 20 hours, with $89 \%$ sensitivity and $75 \%$ 
specificity. Once validated, EALI score criteria could be useful for future clinical trials targeting early treatment of acute lung injury. [PubMed: 23782966]

12*. Festic E, Bansal V, Kor DJ, Gajic O. SpO2/FiO2 Ratio on Hospital Admission Is an Indicator of Early Acute Respiratory Distress Syndrome Development Among Patients at Risk. J Intensive Care Med. 2013 In a secondary analysis of the LIPS cohort, $\mathrm{SpO}_{2} / \mathrm{FiO}_{2}$ measured within the first 6 hours after hospital admission was found to be an independent indicator of ARDS development among patients at risk in a dose-dependent manner. The association with early ARDS development persisted after adjustment in a multivariable logistic regression model for all other LIPS variables, APACHE 2, and comorbid conditions known to affect $\mathrm{SpO}_{2} / \mathrm{FiO}_{2}$.

13**. Ahmed AH, Litell JM, Malinchoc M, Kashyap R, Schiller HJ, Pannu SR, et al. The role of potentially preventable hospital exposures in the development of acute respiratory distress syndrome: a population-based study. Crit Care Med. 2014; 42(1):31-9. This was a populationbased, nested case-control study of consecutive adults who developed ARDS and their matched controls, in a 10-year period. It showed that hospital-acquired adverse events were highly associated with development of ARDS (OR 6.2; 4.0-9.7). Abstracted specific iatrogenic exposures included: medical and surgical adverse events, inadequate empirical antimicrobial treatment, hospital-acquired aspiration, injurious mechanical ventilation, transfusion, and fluid and medication administration. As the rate of adverse hospital exposures and prevalence of ARDS both decreased during the study period, the investigators concluded that prevention of adverse hospital exposures in at-risk patients may limit the development of ARDS. [PubMed: 23982022]

14. Li G, Malinchoc M, Cartin-Ceba R, Venkata CV, Kor DJ, Peters SG, et al. Eight-year trend of acute respiratory distress syndrome: a population-based study in Olmsted County, Minnesota. Am J Respir Crit Care Med. 2011; 183(1):59-66. [PubMed: 20693377]

15. Gajic O, Dara SI, Mendez JL, Adesanya AO, Festic E, Caples SM, et al. Ventilator-associated lung injury in patients without acute lung injury at the onset of mechanical ventilation*. Crit Care Med. 2004; 32(9):1817-24. [PubMed: 15343007]

16. Gajic O, Rana R, Winters JL, Yilmaz M, Mendez JL, Rickman OB, et al. Transfusion-related acute lung injury in the critically ill: prospective nested case-control study. Am J Respir Crit Care Med. 2007; 176(9):886-91. [PubMed: 17626910]

17. Iscimen R, Cartin-Ceba R, Yilmaz M, Khan H, Hubmayr RD, Afessa B, et al. Risk factors for the development of acute lung injury in patients with septic shock: an observational cohort study. Crit Care Med. 2008; 36(5):1518-22. [PubMed: 18434908]

18*. Serpa Neto A, Simonis FD, Barbas CSV, Biehl M, Determann RM, Elmer J, et al. Association between tidal volume size, duration of ventilation, and sedation needs in patients without acute respiratory distress syndrome: an individual patient data meta-analysis. Intensive Care Med. 2014; 40(7):950-7. This individual patient data meta-analysis assessed the associations between tidal volume size, and duration of mechanical ventilation in patients without ARDS at the onset of mechanical ventilation. It suggested that the use of lower tidal volumes in patients without ARDS could be associated with shorter duration of ventilation. [PubMed: 24811940]

19. Albert RK. The role of ventilation-induced surfactant dysfunction and atelectasis in causing acute respiratory distress syndrome. Am J Respir Crit Care Med. 2012 Apr 1; 185(7):702-8. [PubMed: 22227381]

20. Fowler AA, Hamman RF, Good JT, Benson KN, Baird M, Eberle DJ, et al. Adult respiratory distress syndrome: risk with common predispositions. Ann Intern Med. 1983; 98(5 Pt 1):593-7. [PubMed: 6846973]

21 * Lee A. Characteristics and outcomes of patients hospitalized following pulmonary aspiration. Chest. 2014 The retrospective analysis of LIPS cohort data was done to better characterize patients with aspiration, including their potential risk factors and related outcomes, including ARDS. It demonstrated that documented or witnessed aspiration at the time of the hospital admission was independently associated with a significant increase in the risk for ARDS as well as morbidity and mortality.

22*. Kallet RH, Matthay MA. Hyperoxic acute lung injury. Respir Care. 2013; 58(1):123-41. This review examines the pathophysiology of hyperoxia and the associated risks of hyperoxia induced 
acute lung injury (HALI). It proposes the use of important adjunctive therapies for severe hypoxemia, which have been associated with the reduced risk of HALI. [PubMed: 23271823]

23. Dellinger RP, Levy MM, Rhodes A, Annane D, Gerlach H, Opal SM, et al. Surviving sepsis campaign: international guidelines for management of severe sepsis and septic shock: 2012. Crit Care Med. 2013; 41(2):580-637. [PubMed: 23353941]

24. Castellanos-Ortega A, Suberviola B, Garcia-Astudillo LA, Holanda MS, Ortiz F, Llorca J, et al. Impact of the Surviving Sepsis Campaign protocols on hospital length of stay and mortality in septic shock patients: results of a three-year follow-up quasi-experimental study. Crit Care Med. 2010; 38(4):1036-43. [PubMed: 20154597]

25. Schramm GE, Kashyap R, Mullon JJ, Gajic O, Afessa B. Septic shock: a multidisciplinary response team and weekly feedback to clinicians improve the process of care and mortality. Crit Care Med. 2011; 39(2):252-8. [PubMed: 21057312]

26. Zaydfudim V, Dossett LA, Starmer JM, Arbogast PG, Feurer ID, Ray WA, et al. Implementation of a real-time compliance dashboard to help reduce SICU ventilator-associated pneumonia with the ventilator bundle. Arch Surg. 2009; 144(7):656-62. [PubMed: 19620546]

27. Kor DJ, Talmor DS, Banner-Goodspeed VM, Carter RE, Hinds R, Park PK, et al. Lung Injury Prevention with Aspirin (LIPS-A): a protocol for a multicentre randomised clinical trial in medical patients at high risk of acute lung injury. BMJ Open. 2012; 2(5)

28*. Ortiz-Diaz E, Festic E, Gajic O, Levitt JE. Emerging pharmacological therapies for prevention and early treatment of acute lung injury. Semin Respir Crit Care Med. 2013; 34(4):448-58. This review examines novel pharmacological treatments targeting the pathways that may prevent or ameliorate ARDS, as well as current and upcoming clinical trials in pharmacological prevention of ARDS. [PubMed: 23934714]

29**. Perkins GD, Gates S, Park D, Gao F, Knox C, Holloway B, et al. The beta agonist lung injury trial prevention. A randomized controlled trial. Am J Respir Crit Care Med. 2014 Mar 15; 189(6):674-83. This is the first, multicenter randomized controlled trial of a pharmacological agent for prevention of postoperative ARDS. Although the treatment with salmeterol did not prevent ARDS, adverse events were less frequent in the salmeterol group (OR, 0.63; 0.39-0.99), predominantly because of a lower incidence of pneumonia (OR, 0.39; 0.16-0.96). Additionally, in a translational substudy from a single study site, salmeterol reduced some biomarkers of alveolar inflammation and epithelial injury. [PubMed: 24392848]

30. Barnes PJ. Scientific rationale for inhaled combination therapy with long-acting beta2-agonists and corticosteroids. Eur Respir J. 2002; 19(1):182-91. [PubMed: 11843317]

31. Suda K, Tsuruta M, Eom J, Or C, Mui T, Jaw JE, et al. Acute lung injury induces cardiovascular dysfunction: effects of IL-6 and budesonide/formoterol. Am J Respir Cell Mol Biol. 2011; 45(3): 510-6. [PubMed: 21169556]

32. Akapo S, Gupta J, Martinez E, McCrea C, Ye L, Roach M. Compatibility and aerosol characteristics of formoterol fumarate mixed with other nebulizing solutions. Ann Pharmacother. 2008; 42(10):1416-24. [PubMed: 18780805]

33. Dixon B, Schultz MJ, Smith R, Fink JB, Santamaria JD, Campbell DJ. Nebulized heparin is associated with fewer days of mechanical ventilation in critically ill patients: a randomized controlled trial. Crit Care. 2010; 14(5):R180. [PubMed: 20937093]

34. Miller AC, Elamin EM, Suffredini AF. Inhaled anticoagulation regimens for the treatment of smoke inhalation-associated acute lung injury: a systematic review. Crit Care Med. 2014; 42(2): 413-9. [PubMed: 24158173]

35. Gould NS, Gauthier S, Kariya CT, Min E, Huang J, Brian DJ. Hypertonic saline increases lung epithelial lining fluid glutathione and thiocyanate: two protective CFTR-dependent thiols against oxidative injury. Respir Res. 2010; 11:119. [PubMed: 20799947]

36. Wohlauer M, Moore EE, Silliman CC, Fragoso M, Gamboni F, Harr J, et al. Nebulized hypertonic saline attenuates acute lung injury following trauma and hemorrhagic shock via inhibition of matrix metalloproteinase-13. Crit Care Med. 2012; 40(9):2647-53. [PubMed: 22732292]

37. Matthay MA, Ware LB, Zimmerman GA. The acute respiratory distress syndrome. J Clin Invest. 2012; 122(8):2731-40. [PubMed: 22850883]

38. Zarbock A, Ley K. The role of platelets in acute lung injury (ALI). Front Biosci. 2009; 14:150-8. 
39. Zarbock A, Polanowska-Grabowska RK, Ley K. Platelet-neutrophil-interactions: linking hemostasis and inflammation. Blood Rev. 2007; 21(2):99-111. [PubMed: 16987572]

40. Looney MR, Nguyen JX, Hu Y, Van Ziffle JA, Lowell CA, Matthay MA. Platelet depletion and aspirin treatment protect mice in a two-event model of transfusion-related acute lung injury. $\mathrm{J}$ Clin Invest. 2009; 119(11):3450-61. [PubMed: 19809160]

41. Fukunaga K, Kohli P, Bonnans C, Fredenburgh LE, Levy BD. Cyclooxygenase 2 plays a pivotal role in the resolution of acute lung injury. J Immunol. 2005; 174(8):5033-9. [PubMed: 15814734]

42. Erlich JM, Talmor DS, Cartin-Ceba R, Gajic O, Kor DJ. Prehospitalization antiplatelet therapy is associated with a reduced incidence of acute lung injury: a population-based cohort study. Chest. 2011; 139(2):289-95. [PubMed: 20688925]

43. Kor DJ, Erlich J, Gong MN, Malinchoc M, Carter RE, Gajic O, et al. Association of prehospitalization aspirin therapy and acute lung injury: results of a multicenter international observational study of at-risk patients. Crit Care Med. 2011 Nov; 39(11):2393-400. [PubMed: 21725238]

44. Fernandez-Perez ER, Sprung J, Afessa B, Warner DO, Vachon CM, Schroeder DR, et al. Intraoperative ventilator settings and acute lung injury after elective surgery: a nested case control study. Thorax. 2009; 64(2):121-7. [PubMed: 18988659]

45**. Blum JM, Stentz MJ, Dechert R, Jewell E, Engoren M, Rosenberg AL, et al. Preoperative and intraoperative predictors of postoperative acute respiratory distress syndrome in a general surgical population. Anesthesiology. 2013; 118(1):19-29. In this study, the investigators determined the incidence and risk factors for the development of ARDS in the general surgical population by using risk-matched analysis and a combination of clinical and research data sets. The data set, comprised upon the review of common adult surgical procedures over a 5-year period using an anesthesia information system was merged with an ARDS registry and an institutional death registry. After matching and multivariate regression, intraoperative factors associated with ARDS development were determined. Although the incidence of ARDS in general surgical population was found to be low $(0.2 \%)$, significant intraoperative predictors were found to be median drive pressure, $\mathrm{FiO} 2$, crystalloid volume, and transfusion. [PubMed: 23221870]

46. Watkins TR, Nathens AB, Cooke CR, Psaty BM, Maier RV, Cuschieri J, et al. Acute respiratory distress syndrome after trauma: development and validation of a predictive model. Crit Care Med. 2012; 40(8):2295-303. [PubMed: 22809905]

47. Alsara A, Warner DO, Li G, Herasevich V, Gajic O, Kor DJ. Derivation and validation of automated electronic search strategies to identify pertinent risk factors for postoperative acute lung injury. Mayo Clin Proc. 2011 May; 86(5):382-8. [PubMed: 21531881]

48. Ranieri VM, Rubenfeld GD, Thompson BT, Ferguson ND, Caldwell E, Fan E, et al. Acute respiratory distress syndrome: the Berlin Definition. JAMA. 2012 Jun 20; 307(23):2526-33. [PubMed: 22797452]

49. Kushimoto S, Taira Y, Kitazawa Y, Okuchi K, Sakamoto T, Ishikura H, et al. The clinical usefulness of extravascular lung water and pulmonary vascular permeability index to diagnose and characterize pulmonary edema: a prospective multicenter study on the quantitative differential diagnostic definition for acute lung injury/acute respiratory distress syndrome. Crit Care. 2012; 16:R232. [PubMed: 23232188]

50. LeTourneau JL, Pinney J, Phillips CR. Extravascular lung water predicts progression to acute lung injury in patients with increased risk*. Crit Care Med. 2012; 40(3):847-54. [PubMed: 22036857] 


\section{Key points}

- Novel risk prediction tools can assist in timely identification of patients at risk of developing ARDS.

- Improvements in clinical care delivery have been associated with decreased incidence of hospital acquired ARDS.

- Prevention and early treatment of ARDS is a current priority in investigative efforts to curtail this devastating syndrome. 


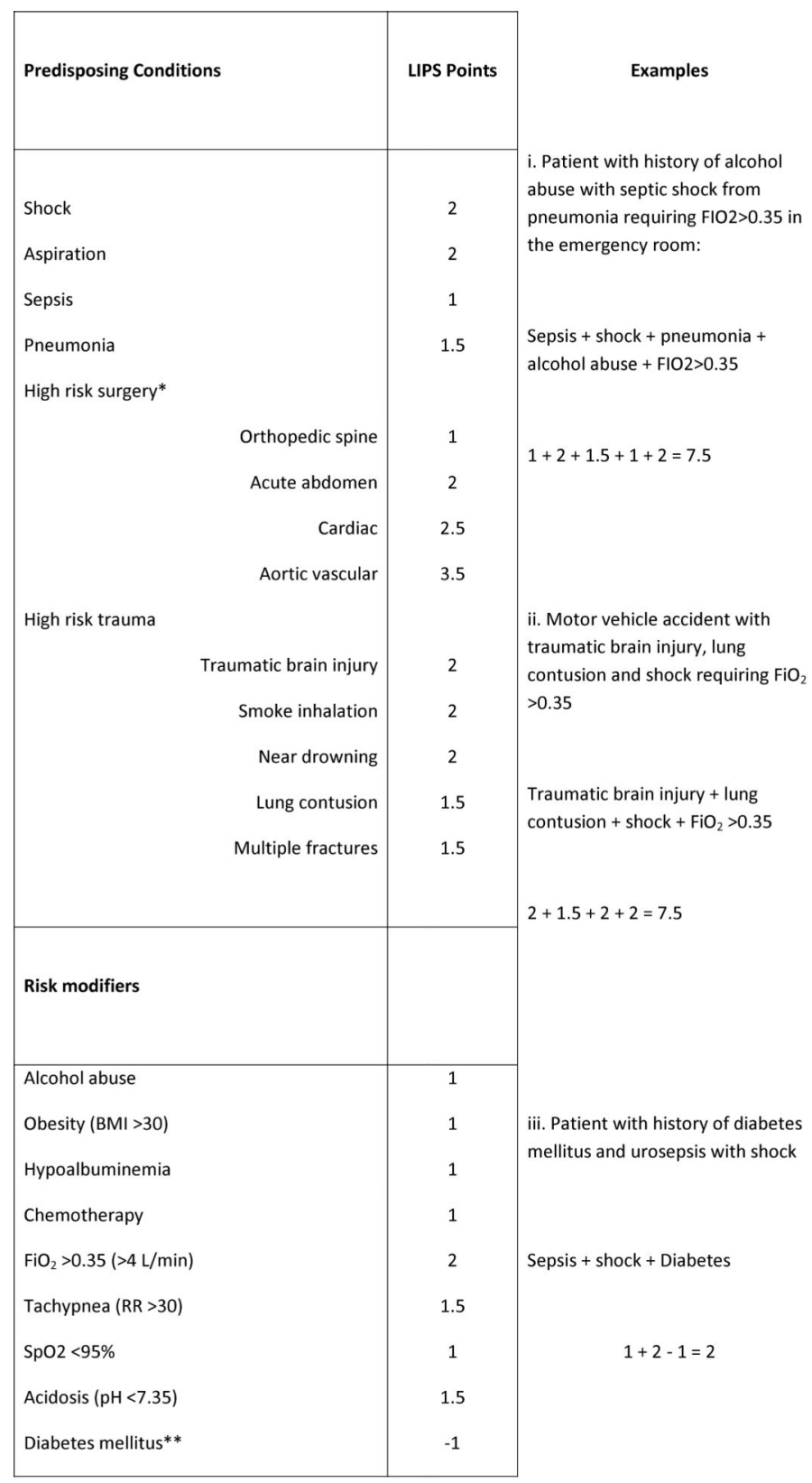

Abbreviations: $\mathrm{BMI}=$ body mass index; $\mathrm{RR}=$ respiratory rate; $\mathrm{SpO}=$ =xygen saturation by pulse oximetry

*Add 1.5 points if emergency surgery; tonly if sepsis present.

Figure 1.

Lung Injury Prediction Score (LIPS) calculation worksheet.

From: Gajic O, Dabbagh O, Park PK, et al. Early identification of patients at risk of acute lung injury: evaluation of lung injury prediction score in a multicenter cohort study. American Journal of Respiratory \& Critical Care Medicine. 2011;183(4):462-70. [8] 


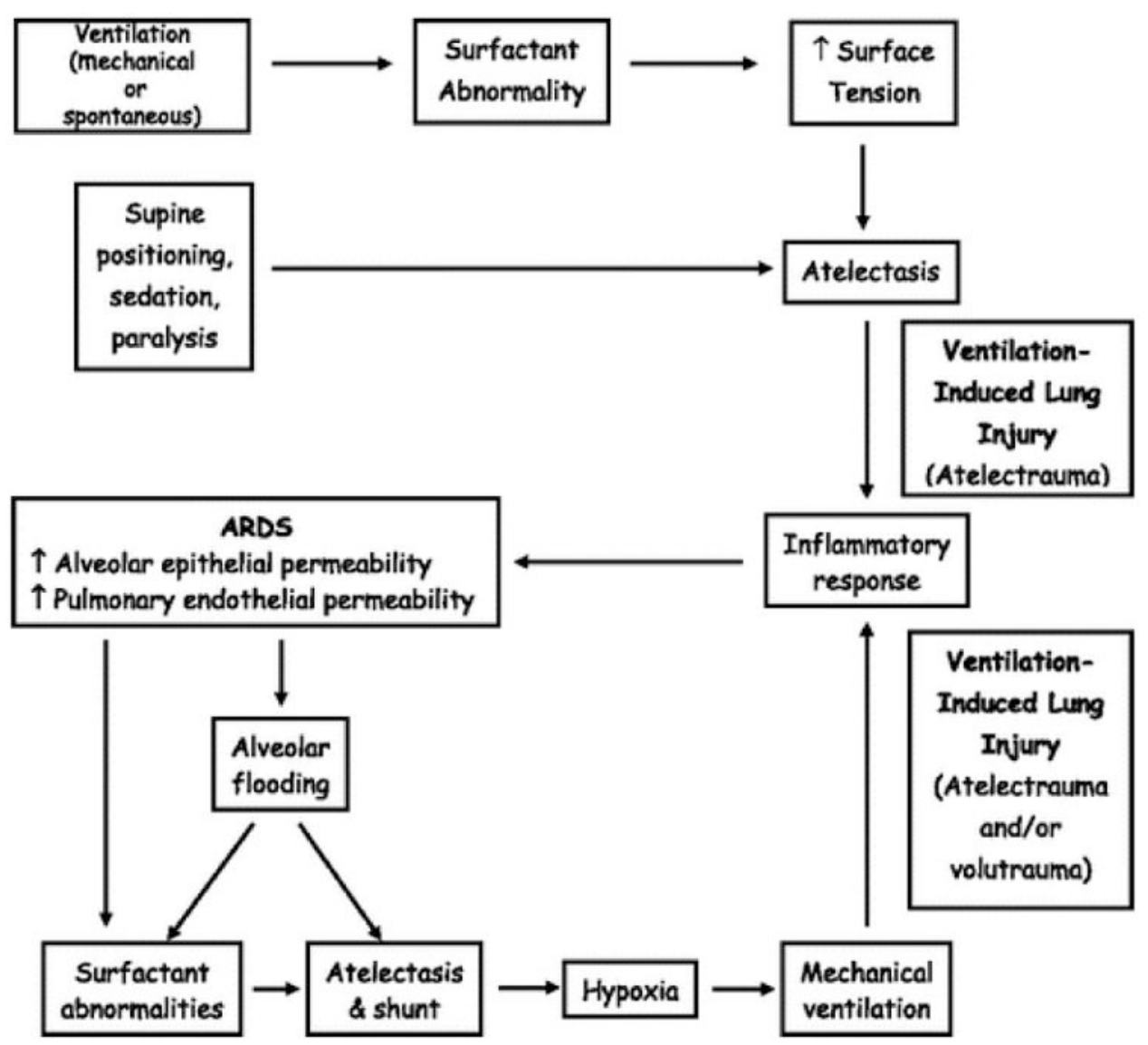

Figure 2.

Proposed alternative pathophysiology of ARDS.

From: Albert RK. The role of ventilation-induced surfactant dysfunction and atelectasis in causing acute respiratory distress syndrome. Am J RespCrit Care Med 2012;185(7):702-708. [19] 


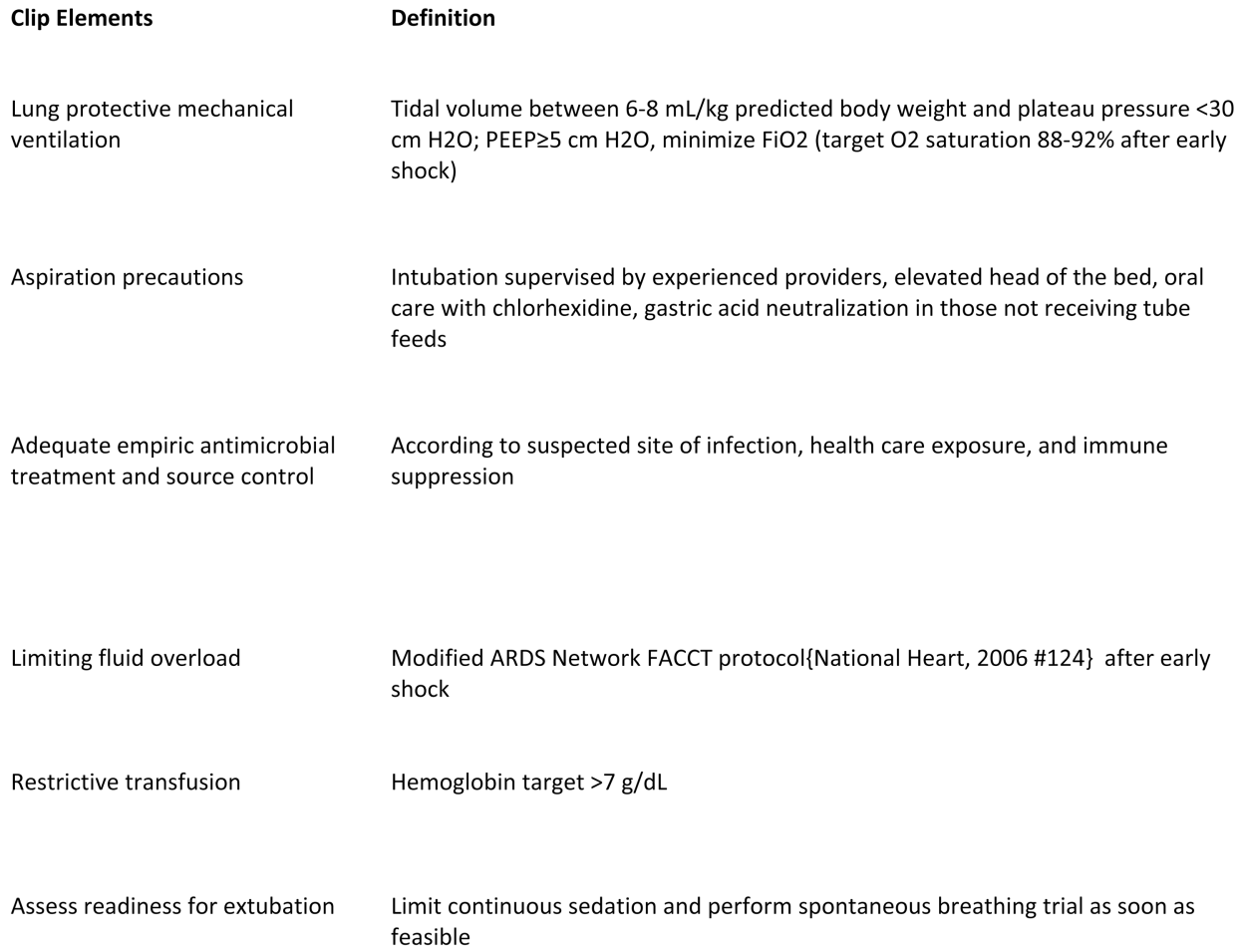
feasible

Modified ARDS Network FACCT protocol\{National Heart, $2006 \# 124\}$ after early shock

Hemoglobin target $>7 \mathrm{~g} / \mathrm{dL}$

Limit continuous sedation and perform spontaneous breathing trial as soon as

Tidal volume between $6-8 \mathrm{~mL} / \mathrm{kg}$ predicted body weight and plateau pressure $<30$ $\mathrm{cm} \mathrm{H} 2 \mathrm{O}$; PEEP $\geq 5 \mathrm{~cm} \mathrm{H} 2 \mathrm{O}$, minimize FiO2 (target $\mathrm{O} 2$ saturation $88-92 \%$ after early shock)

Intubation supervised by experienced providers, elevated head of the bed, ora care with chlorhexidine, gastric acid neutralization in those not receiving tube feeds

According to suspected site of infection, health care exposure, and immune suppression

Abbreviations: $\mathrm{PEEP}=$ positive end-expiratory pressure; $\mathrm{FiO} 2=$ fractional inspired oxygen concentration.

Figure 3.

Checklist for Lung Injury Prevention (CLIP).

Curr Opin Crit Care. Author manuscript; available in PMC 2016 February 01. 


\begin{tabular}{|c|c|c|c|}
\hline Medication & Mechanism of action & Animal Studies & Human Studies \\
\hline Aspirin & $\begin{array}{l}\text { Inhibition of platelet mediated } \\
\text { cyclooxygenase metabolism involved in } \\
\text { bronchoconstriction and vasoconstriction } \\
\text { and inhibits platelet-neutrophil- } \\
\text { endothelial interactions. }\end{array}$ & $\begin{array}{l}\text { Mice treated with aspirin have } \\
\text { less pulmonary platelet and } \\
\text { neutrophil sequestration. Also } \\
\text { treated animals have improved } \\
\text { survival and decreased lung } \\
\text { weights. }\end{array}$ & $\begin{array}{l}\text { Observational studies conflicting } \\
\text { in terms of their findings. The } \\
\text { largest cohort found a non- } \\
\text { significant trend toward a } \\
\text { protective effect. }\end{array}$ \\
\hline Systemic Corticosteroids & $\begin{array}{l}\text { Multi-potent; inhibit inflammatory } \\
\text { cytokines; induced apoptosis of } \\
\text { macrophages; maintain endothelial } \\
\text { cellular barrier. }\end{array}$ & $\begin{array}{l}\text { Majority show improvement of } \\
\text { hypoxemia, pulmonary vascular } \\
\text { pressure and extra-vascular lung } \\
\text { water. }\end{array}$ & $\begin{array}{l}\text { Older studies performed in the } \\
\text { 1980s show no benefit in } \\
\text { administering short course high- } \\
\text { dose steroids. }\end{array}$ \\
\hline Inhaled Heparin & $\begin{array}{l}\text { In addition to potentiating anti-thrombin- } \\
\text { III, inhibits adhesion of neutrophils to } \\
\text { endothelium and degrades intravascular } \\
\text { and bronchial fibrin. }\end{array}$ & $\begin{array}{l}\text { Conflicting results with } \\
\text { improvement of hypoxemia } \\
\text { histology scores and shunt } \\
\text { fraction. }\end{array}$ & No published human studies. \\
\hline Inhaled Corticosteroids & $\begin{array}{l}\text { Same as systemic corticosteroids. In } \\
\text { theory, might spare patients from } \\
\text { hyperglycemia, myopathy, super-infection, } \\
\text { etc. }\end{array}$ & $\begin{array}{l}\text { Most studies conducted in mice } \\
\text { indicate that physiological } \\
\text { surrogates are improved by } \\
\text { treatment prior to or after } \\
\text { direct/indirect lung injury. }\end{array}$ & No published human studies. \\
\hline Inhaled beta-agonists & $\begin{array}{l}\text { Enhanced alveolar fluid clearance and } \\
\text { inhibits neutrophil adhesion to the } \\
\text { endothelium. }\end{array}$ & $\begin{array}{l}\text { Improved pulmonary } \\
\text { mechanics;decrease neutrophil } \\
\text { sequestration, inflammatory } \\
\text { cytokine concentrations and } \\
\text { enhanced surfactant secretion. }\end{array}$ & $\begin{array}{l}\text { One published human study,(29) } \\
\text { no difference in ARDS incidence } \\
\text { but less pulmonary complications, } \\
\text { mainly pneumonia.Another study } \\
\text { found treatment prevented high } \\
\text { altitude pulmonary edema. }\end{array}$ \\
\hline Statins & $\begin{array}{l}\text { Decreases inflammatory cytokine levels, } \\
\text { adhesion molecule expression, and } \\
\text { neutrophil proliferation. }\end{array}$ & $\begin{array}{l}\text { Improvement in oxygenation, } \\
\text { hemodynamic surrogates, } \\
\text { neutrophil sequestration and } \\
\text { decreased cytokine } \\
\text { concentration. }\end{array}$ & $\begin{array}{l}\text { Human observational studies } \\
\text { have not been consistent. One } \\
\text { study showed a protective effect } \\
\text { while 2, including largest cohort, } \\
\text { did not. }\end{array}$ \\
\hline $\begin{array}{l}\text { Renin-angiotensin axis } \\
\text { blockers }\end{array}$ & $\begin{array}{l}\text { Angiotensin- } 2 \text { positively modulates } \\
\text { nuclear factor- } \mathrm{\beta} \beta \text { gene expression. ACE } \\
\text { type } 2 \text { receptor with angiotensin as its } \\
\text { ligand, prevents endothelial damage. }\end{array}$ & $\begin{array}{l}\text { Effective in preventing } \\
\text { endothelial damage and } \\
\text { inflammatory cytokine } \\
\text { expression. }\end{array}$ & $\begin{array}{l}\text { Two observational studies } \\
\text { showed a protective effect. }\end{array}$ \\
\hline $\begin{array}{l}\text { Peroxisome Proliferator } \\
\text { Receptor agonists }\end{array}$ & $\begin{array}{l}\text { Nuclear receptor superfamily related to } \\
\text { the retinoid, steroid and thyroid receptors } \\
\text { with three subtypes. They decrease } \\
\text { inflammatory cytokine expression, } \\
\text { neutrophil and macrophage chemotaxis } \\
\text { plus inhibit oxidative burst in neutrophils. }\end{array}$ & $\begin{array}{l}\text { Decreased wet to dry ratios, } \\
\text { inflammatory cytokine expression } \\
\text { and improved static compliance. }\end{array}$ & No human studies to date. \\
\hline Curcumin & $\begin{array}{l}\text { Up-regulation of PPAR- } \gamma \text { in various } \\
\text { inflammatory cells (neutrophils, } \\
\text { monocytes, T lymphocytes, endothelial } \\
\text { and epithelial cells). Down-regulation of } \\
\text { inflammatory transcription factors, } \\
\text { enzymes and cytokines. }\end{array}$ & $\begin{array}{l}\text { Decreased wet to dry ratios, and } \\
\text { inflammatory cytokine secretion. }\end{array}$ & No human studies to date. \\
\hline
\end{tabular}

Figure 4.

Emerging pharmacological therapies for ARDS prevention.

Modified from: Ortiz-Diaz E, Festic E, Gajic O, Levitt JE. Emerging pharmacological therapies for prevention and early treatment of acute lung injury. Seminars in Respiratory and Critical Care Medicine. 2013:34(4):448-458. [28] 